\title{
An Alternative and Convenient Synthesis of Oct-7-enal, a Naturally-Occurring Aldehyde Isolated from the Japanese Thistle Cirsium dipsacolepis
}

\author{
Andrea B. J. Bracca and Teodoro S. Kaufman* \\ Instituto de Química Rosario and Facultad de Ciencias Bioquímicas y Farmacéuticas, Universidad Nacional de Rosario, \\ Suipacha 531, S2002LRK Rosario, Argentina
}

\begin{abstract}
Esse trabalho descreve a síntese do oct-7-enal, um aldeído natural, isolado do cardo japonês Cirsium dipsacolepis. O produto natural foi preparado em cinco etapas com bom rendimento, partindo-se do pentano-1,5-diol.
\end{abstract}

A new synthesis of oct-7-enal, a naturally-occurring unsaturated aldehyde isolated from the Japanese thistle Cirsium dipsacolepis, is reported. The natural product was prepared in five steps and with good overall yield from pentane-1,5-diol.

Keywords: chemical synthesis, oct-7-enal, Cirsium dipsacolepis, natural product

Stephaoxocanidine (1) and eletefine (2) are two members of the recently uncovered family of stephaoxocane alkaloids, isolated from Menispermaceae of the Far East and Brazil, respectively. ${ }^{1}$ We have recently reported that tricyclic analogs of the stephaoxocanes bearing their 1,9-oxaazaphenalene motif exhibit interesting acetylcholinesterase inhibitory activity. ${ }^{2}$

In the course of our studies ${ }^{3}$ towards the synthesis of desoxystephaoxocanidine (3) and its analogs, and taking into account the retrosynthetic approach shown in Scheme 1 for the elaboration of tricyclic ketone 4 through the intermediacy of benzocyclodecenyl alcohol $\mathbf{5}$, employing the known bromoaldehyde $7^{4}$ and the related styrene derivative $\mathbf{6}$, we required a simple and efficient synthetic route towards oct-7-enal $(\mathbf{8})$.

Oct-7-enal is a naturally-occurring unsaturated aldehyde, isolated from the volatile oil of the thistle Cirsium dipsacolepis (Asteraceae). ${ }^{5}$ Known as yamagobo, this is a perennial herb that grows in Japan on dry plains, which is the source of bioactive compounds ${ }^{6}$ and which edible roots, once pickled, are used to accompany meat-based foods due to their extraordinary flavor. The unsaturated aldehyde has been synthesized in widely different scales and diverse purposes, by dihydroxylation of one of the double bonds of 1,8-nonadiene, followed by oxidative fission of the resulting diol, ${ }^{7,8}$ as well as by partial hydroboration-oxidation and further oxidation of 1,7-octadiene ${ }^{9}$ and biochemical

*e-mail: kaufman@iquios.gov.ar oxidation of this diene with Pseudomonas oleovorans monooxygenase. ${ }^{10}$ Also, copper (I) and lead (IV)-catalyzed oxidative ring opening of cyclooctanol ${ }^{11}$ were employed for its synthesis, as well as copper (I)-assisted conjugate addition of 4-pentenylmagnesium bromide to acrolein diethyl acetal, followed by acid hydrolysis of the resulting enol ether, ${ }^{12}$ isomerization of cyclooctene oxide employing solid acids and bases, ${ }^{13}$ and isomerization of 2,7-octadien1-ol on copper, chromium and zinc composite catalysts at $180-250{ }^{\circ} \mathrm{C}^{14}$ or on a copper catalyst. ${ }^{15}$

However, these approaches are not exempt from serious drawbacks, such as low yields, ${ }^{7}$ use of harsh conditions, ${ }^{13,14}$ requirement of expensive starting materials, ${ }^{7,10,12}$ use of special or not readily available catalysts or co-factors, ${ }^{10}$ inconvenient separation conditions, ${ }^{14}$ such as preparative HPLC, ${ }^{7}$ and the concomitant production of unwanted byproducts, ${ }^{13}$ sometimes the aldehyde $\mathbf{8}$ being only a minor product. ${ }^{11}$

The reactivity of $\mathbf{8}$ as a model in the selective reduction of carbonyls, mediated by 2-propanol in supercritical fluids, has been studied. ${ }^{16}$ Interestingly, the use of an impure sample of oct-7-enal has also been informed. ${ }^{17}$

\section{Results and Discussion}

Therefore, here we wish to report an alternative, straightforward and convenient synthesis of oct-7-enal in five steps, from the readily available pentane-1,5-diol (9). As shown in Scheme 2, this comprised the selective 


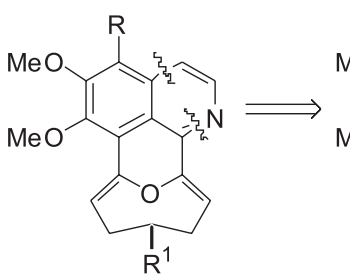

$1 \mathrm{R}=\mathrm{H}, \mathrm{R}^{1}=\mathrm{OH}$

$2 \mathrm{R}=\mathrm{OMe}, \mathrm{R}^{1}=\mathrm{OH}$

$3 \mathrm{R}=\mathrm{R}^{1}=\mathrm{H}$

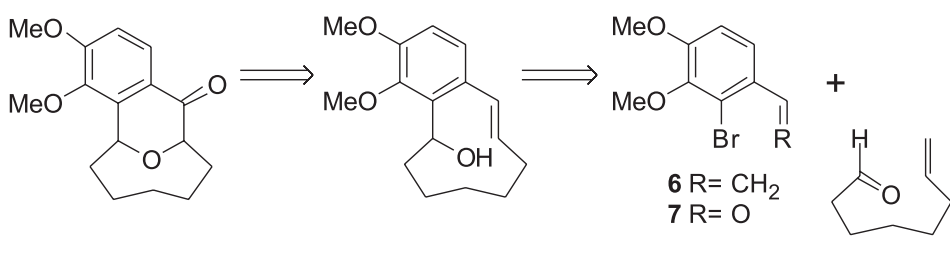

5

8

Scheme 1. A retrosynthetic analysis of stephaoxocanidine.

monoprotection of one of the hydroxyl groups of the starting material as tert-butyl dimethylsilyl (TBS) ether employing TBSCl and $\mathrm{NaH}$ in dry THF, which furnished $60 \%$ of compound 10 , a yield that was similar to that achieved when TBSCl and imidazole in anhydrous DMF were used. ${ }^{18}$ In turn, alcohol $\mathbf{1 0}$ was transformed into the related sulfonic ester $\mathbf{1 1}$ (86\% yield) with tosyl chloride and triethylamine, under conventional conditions, setting the stage for chain elongation. There are scattered precedents of the direct displacement of tosylates by the allyl Grignard; ${ }^{19}$ however, it was considered convenient to employ copper (I) iodide assistance, a more established alternative. ${ }^{20}$ The need of several equivalents of low order cuprates to achieve high yields has been recognized as one of their major drawbacks; ${ }^{21}$ therefore, use of excess allylmagnesium bromide was key for attaining high conversions from 11. Not unexpectedly, when a threefold excess of allyl Grignard was employed, $76 \%$ of $\mathbf{1 2}$ was obtained; this was improved to $84 \%$ upon use of a six-fold excess of the organometallic reagent and reached $92 \%$ when a ten times excess was added.

Next, the silyl ether was conveniently deprotected with TBAF in THF to smoothly provide almost quantitative yields of oct-7-enol (13), which was finally oxidized to the desired aldehyde $\mathbf{8}$ in $80 \%$, employing $\mathrm{PCC} / \mathrm{Al}_{2} \mathrm{O}_{3}$; the same oxidation was also successfully carried out in $78 \%$ yield, employing Dess-Martin periodinane in anhydrous $\mathrm{CH}_{2} \mathrm{Cl}_{2}$. Spectral data of the synthetic compound were in agreement with the literature. ${ }^{7}$

In conclusion, an alternative and simple synthesis of the natural product oct-7-enal $(\mathbf{8})$ was achieved in five steps and $38 \%$ overall yield, from commercially available pentane1,5-diol. The synthesis involved differential protection of both hydroxyl groups of the diol with inclusion of a suitable leaving group, which after copper (I)-assisted displacement with an allyl Grignard furnished the required 8 -carbon chain. Mild deprotection and functional group interconversion culminated in the synthesis of $\mathbf{8}$. The main advantages of the proposed sequence are simplicity, ease of purification of the intermediate products and

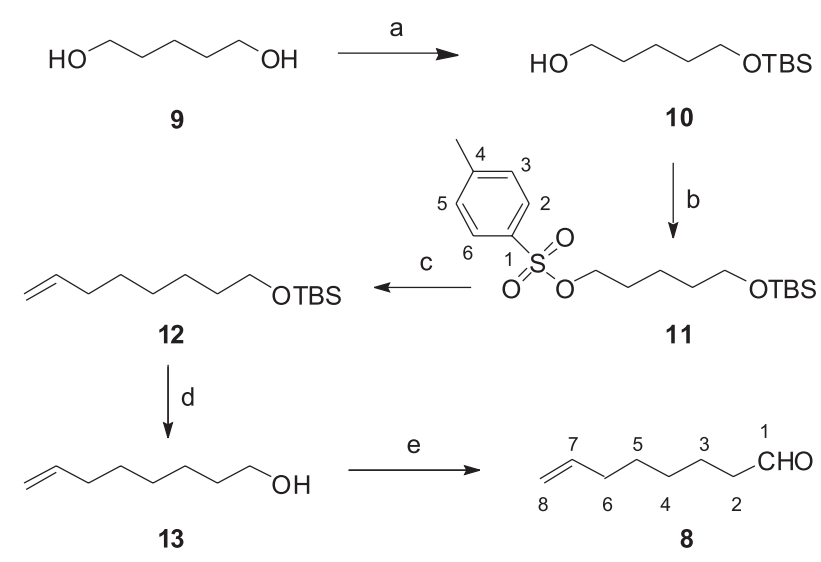

Scheme 2. Reagents and conditions: a) TBSCl (1 equiv.), NaH, THF, RT, $1 \mathrm{~h}(60 \%)$; b) TsCl, $\mathrm{Et}_{3} \mathrm{~N}$, DMAP (cat.), $\mathrm{CH}_{2} \mathrm{Cl}_{2}$, RT, overnight (86\%); c) $\mathrm{H}_{2} \mathrm{C}=\mathrm{CHCH}_{2} \mathrm{MgBr}$, CuI, Et $\mathrm{O},-20^{\circ} \mathrm{C} \rightarrow \mathrm{RT}, 4.5 \mathrm{~h}(92 \%)$; d) TBAF, THF,

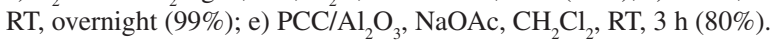

ready accessibility of starting materials and reagents. Its application to the elaboration of analogs of stephaoxocanes will be reported in due course.

\section{Experimental}

\section{General procedures}

FT-IR spectra were determined with a Shimadzu IR Prestige 21 spectrophotometer. The ${ }^{1} \mathrm{H}$ and ${ }^{13} \mathrm{C}$ NMR spectra were acquired in $\mathrm{CDCl}_{3}$ employing TMS as internal standard, with a Bruker Avance 300 spectrometer operating at 300.13 and $75.46 \mathrm{MHz}$, respectively; coupling constants $(J)$ are expressed in Hertz. The asterisk $(*)$ indicates that assignments can be exchanged; mass spectra were acquired at the National University of Tucumán. The reactions were carried out under dry argon atmospheres, employing ovendried glassware. All new compounds gave single spots on TLC plates run in different hexane-EtOAc solvent systems. Spots were visualized by spraying with ethanolic $p$-anisaldehyde/ sulfuric acid reagent and careful heating. Visualization by exposure to UV light (254 and $365 \mathrm{~nm}$ ), preceded spraying in case of compounds with suitable chromophors. Flash column chromatographies were carried out with silica gel $60 \mathrm{H}$, eluting 
with mixtures of hexane-EtOAc under positive pressure and employing stepwise gradient techniques.

\section{5-(tert-Butyl-dimethyl-silanyloxy)-pentan-1-ol (10)}

A solution of pentane-1,5-diol (1000 mg, $9.62 \mathrm{mmol})$ in anhydrous THF $(20 \mathrm{~mL})$ was treated with $\mathrm{NaH}(50 \%$ in mineral oil, $462 \mathrm{mg}, 9.62 \mathrm{mmol}$ ); after stirring at room temperature during $1 \mathrm{~h}$, a solution of tert-butyl dimethylsilyl chloride $(1452 \mathrm{mg}, 9.62 \mathrm{mmol})$ in THF $(10 \mathrm{~mL})$ was added dropwise and the reaction was left to proceed for $3 \mathrm{~h}$ at room temperature. Then, brine $(10 \mathrm{~mL})$ was added and the reaction products were extracted with EtOAc $(3 \times 25 \mathrm{~mL})$. The combined organic extracts were washed once with brine $(5 \mathrm{~mL})$, dried over $\mathrm{Na}_{2} \mathrm{SO}_{4}$, concentrated under reduced pressure and chromatographed, furnishing monoprotected diol 10 (1495 mg, 60\%), as an oil. IR (KBr) $v_{\text {max }} / \mathrm{cm}^{-1}: 3354,2950,2858,1473,1389,1258,1101,1006$, 836 and $775 ;{ }^{1} \mathrm{H}$ NMR $\delta 0.05$ [s, $\left.6 \mathrm{H}, \mathrm{Si}\left(\mathrm{CH}_{3}\right)_{2}\right], 0.89$ [s, 9H, $\left.\mathrm{C}\left(\mathrm{CH}_{3}\right)_{3}\right], 1.40-1.59$ (m, 6H, H-2, H-3 and $\left.\mathrm{H}-4\right), 3.64$ (dt, 4H, $J 5.4$ and 7.0, $\mathrm{H}-1$ and $\mathrm{H}-5) ;{ }^{13} \mathrm{C}$ NMR $\delta-5,40$

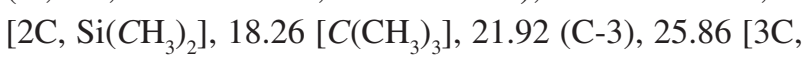
$\left.\mathrm{C}\left(\mathrm{CH}_{3}\right)_{3}\right], 32.39$ (2C, $\mathrm{C}-2$ and $\left.\mathrm{C}-4\right), 62.84(\mathrm{C}-5)^{*}$ and 63.00 (C-1). ${ }^{*} \mathrm{MS}(\mathrm{CI}), \mathrm{m} / \mathrm{z}(\%): 219\left[(\mathrm{M}+1)^{+}, 100\right], 201[(\mathrm{M}-$ $\left.\left.\mathrm{H}_{2} \mathrm{O}+1\right)^{+}, 32\right], 155$ (6), 127 (4), 85 (12) and 69 (24).

\section{5-(tert-Butyl-dimethyl-silanyloxy)-pentyl-4-methylbenze-} nesulfonate (11)

Triethylamine $(1.05 \mathrm{~mL}, 7.56 \mathrm{mmol})$ and DMAP (50 $\mathrm{mg}, 0.41 \mathrm{mmol}$ ) were added to a solution of alcohol $\mathbf{1 0}$ (1104 mg, $5.04 \mathrm{mmol}$ ) in $\mathrm{CH}_{2} \mathrm{Cl}_{2}(16 \mathrm{~mL})$. The solution was cooled in an ice-water bath and then treated portionwise with tosyl chloride (1059 mg, $5.55 \mathrm{mmol})$. After stirring overnight at room temperature, a saturated solution of $\mathrm{NH}_{4} \mathrm{Cl}$ was added $(10 \mathrm{~mL})$ and the reaction products were extracted with $\mathrm{CH}_{2} \mathrm{Cl}_{2}(3 \times 25 \mathrm{~mL})$. The organic extracts were combined, washed with brine $(10 \mathrm{~mL})$, dried $\left(\mathrm{Na}_{2} \mathrm{SO}_{4}\right)$, concentrated under reduced pressure and chromatographed, furnishing tosylate $\mathbf{1 1}(1618 \mathrm{mg}, 86 \%)$, as an oil. IR (KBr) $v_{\text {max }} / \mathrm{cm}^{-1}: 2954,2858,1599,1472,1362,1257,1189,1098$, 962, 835, 776 and $664 ;{ }^{1} \mathrm{H}$ NMR $\delta 0.04$ [s, 6H, Si $\left.\left(\mathrm{CH}_{3}\right)_{2}\right]$, 0.87 [s, 9H, C( $\left.\left.\mathrm{CH}_{3}\right)_{3}\right], 1.30-1.39$ (m, 2H, H-3), 1.40-1.51 (m, 2H, H-4), 1.66 (dt, 2H, J 6.6 and 14.7, H-2), 2.45 (s, $3 \mathrm{H}, \mathrm{ArCH}_{3}$ of Ts), 3.55 (t, 2H, J 6.2, H-5), 4.03 (t, 2H, J 6.6, $\mathrm{H}-1), 7.34$ (d, 2H, $J$ 8.5, ArH-3 and ArH-5 of Ts) and 7.79 (d, $2 \mathrm{H}, J$ 8.5, ArH-2 and ArH-6 of Ts); ${ }^{13} \mathrm{C}$ NMR $\delta-5,45$

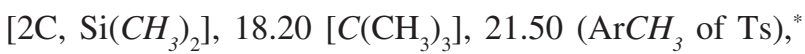
$21.68(\mathrm{C}-3),{ }^{*} 25.82\left[3 \mathrm{C}, \mathrm{C}\left(\mathrm{CH}_{3}\right)_{3}\right], 28.52(\mathrm{C}-2), 31.93(\mathrm{C}-$ 4), 62.61 (C-5), 70.45 (C-1), 127.76 (2C, Ar-2 and Ar-6 of Ts), 129.68 (2C, Ar-3 and Ar-5 of Ts), 133.16 (Ar-1 of Ts) and 144.49 (Ar-4 of Ts). MS (CI), $m / z(\%): 373\left[(\mathrm{M}+1)^{+}\right.$, 78], 315 (10) and 201 (100).
tert-Butyl-dimethyl-oct-7-en-1-yloxy-silane (12)

Anhydrous copper (I) iodide ( $255 \mathrm{mg}, 1.34 \mathrm{mmol}$ ) was added to a solution of tosylate $\mathbf{1 1}(100 \mathrm{mg}, 0.27 \mathrm{mmol})$ in anhydrous $\mathrm{Et}_{2} \mathrm{O}(1 \mathrm{~mL})$; the resulting suspension was cooled to $-20{ }^{\circ} \mathrm{C}$ and treated with freshly prepared 1.83 mol L-1 solution of allylmagnesium bromide in $\mathrm{Et}_{2} \mathrm{O}$ $(1.46 \mathrm{~mL}, 2.68 \mathrm{mmol})$. The reaction was left to warm to room temperature and further stirred for $4.5 \mathrm{~h}$, when a saturated solution of $\mathrm{NH}_{4} \mathrm{Cl}(10 \mathrm{~mL})$ was added and the reaction products were extracted with EtOAc $(3 \times 15$ $\mathrm{mL})$. The combined organic extracts were washed with brine $(10 \mathrm{~mL})$, dried $\left(\mathrm{Na}_{2} \mathrm{SO}_{4}\right)$, concentrated in vacuo and chromatographed, providing silyl ether $\mathbf{1 2}(60 \mathrm{mg}, 92 \%)$ as an oil. IR (KBr) $v_{\max } / \mathrm{cm}^{-1}: 2955,2858,1641,1473,1388$, 1256, 1102, 910, 836, 774 and 661; ${ }^{1} \mathrm{H}$ NMR $\delta 0.05$ [s, 6H, $\mathrm{Si}\left(\mathrm{CH}_{3}\right)_{2}$ ], 0.89 [s, 9H, $\left.\mathrm{C}\left(\mathrm{CH}_{3}\right)_{3}\right], 1.25-1.45(\mathrm{~m}, 6 \mathrm{H}, \mathrm{H}-3$, H-4 and H-5), 1.51 (bt, 2H, J 6.8, H-6), 2.04 (bq, 2H, J 6.6, H-2), 3.60 (dd, 2H, $J 5.5$ and 7.5, H-1), 4.92 (bdd, 1H, $J$ 2.0 and 9.0, H-8), 4.98 (bdd, $1 \mathrm{H}, J 2.0$ and 18.4, H-8) and 5.79 (dddd, $1 \mathrm{H}, J 6.8,6.8,9.0$, and $18.4, \mathrm{H}-7$ ); ${ }^{13} \mathrm{C}$ NMR $\delta$ $-5,38\left[2 \mathrm{C}, \mathrm{Si}\left(\mathrm{CH}_{3}\right)_{2}\right], 18.26\left[\mathrm{C}\left(\mathrm{CH}_{3}\right)_{3}\right], 25.56(\mathrm{C}-3), 25.87$ [3C, $\left.\mathrm{C}\left(\mathrm{CH}_{3}\right)_{3}\right], 28.81$ (2C, C-4 and C-5), $32.72(\mathrm{C}-2), 33.63$ (C-6), 63.16 (C-1), 114.04 (C-8) and 139.02 (C-7). MS (CI), $\mathrm{m} / \mathrm{z}(\%): 243\left[(\mathrm{M}+1)^{+}, 12\right], 185$ (15), 127 (25), $111(80)$ and 99 (39), 85 (69), 71 (84), 57 (100) and 43 (82).

\section{Oct-7-enol (13)}

A solution of silyl ether $\mathbf{1 2}(704 \mathrm{mg}, 2.91 \mathrm{mmol})$ in $\mathrm{Et}_{2} \mathrm{O}(10 \mathrm{~mL})$, was treated with $1 \mathrm{M} \mathrm{TBAF}$ in THF $(5.2 \mathrm{~mL}$, $5.2 \mathrm{mmol}$ ). After stirring overnight at room temperature, the solvent was removed under reduced pressure and the remaining oil was chromatographed, furnishing $\mathbf{1 3}$ (368 mg, 99\%), as an oil. IR (KBr) $v_{\max } / \mathrm{cm}^{-1}: 3554,2928$, 2857, 1641, 1435, 1254, 1057, 908, 837 and 783; ${ }^{1} \mathrm{H}$ NMR $\delta$ 1.30-1.44 (m, 6H, H-3, H-4 and H-5), 1.57 (quintet, $2 \mathrm{H}$, $J$ 6.6, H-2), 2.05 (bq, 2H, J 7.2, H-6), 3.63 (t, 2H, $J$ 6.6, H-1), 4.94 (ddt, 1H, J 1.2, 2.2 and 10.2, H-8), 5.00 (dq, $1 \mathrm{H}, J 2.0$ and $17.4, \mathrm{H}-8)$ and $5.81(\mathrm{ddt}, 1 \mathrm{H}, J 6.6,10.2$ and 17.4, H-7); ${ }^{13} \mathrm{C}$ NMR $\delta 25.46$ (C-3), 28.73 (C-4), ${ }^{*} 28.75$ (C-5), 32.60 (C-2), 33.57 (C-6), 62.83 (C-1), 114.11 (C-8) and $138.91(\mathrm{C}-7)$. MS (CI), $m / z(\%): 129\left[(\mathrm{M}+1)^{+}, 3\right], 111$ (8), 73 (100), 69 (19) and 55 (7).

\section{Oct-7-enal (8)}

Anhydrous sodium acetate $(32 \mathrm{mg})$ and $\mathrm{PCC} / \mathrm{Al}_{2} \mathrm{O}_{3}(562$ $\mathrm{mg}$ ) were successively added to a solution of alcohol $\mathbf{1 3}$ (25 mg, $0.20 \mathrm{mmol}$ ) in $\mathrm{CH}_{2} \mathrm{Cl}_{2}(2.5 \mathrm{~mL}$ ), and the resulting suspension was stirred at room temperature until complete consumption of the starting alcohol. Then, the solids were filtered through a column of silica gel, washed with $\mathrm{CH}_{2} \mathrm{Cl}_{2}$ $(2 \mathrm{~mL})$ and the solvent was distilled off, affording $8(25 \mathrm{mg}$, 
$80 \%)$, as an oil. IR (KBr) $v_{\max } / \mathrm{cm}^{-1}: 2926,2855,1726,1639$, 1462, 1258, 1078, 910, 837 and 783; ${ }^{1} \mathrm{H}$ NMR $\delta$ 1.30-1.46 (m, 4H, H-4 and H-5), 1.55-170 (broad quintet, $2 \mathrm{H}, J$ 6.8, H-3); 2.09 (bq, 2H, J 6.8, H-6), 2.45 (dt, 2H, J 1.6 and 7.3, H-2), 4.97 (ddt, 1H, J 1.6, 2.0 and 10.1, H-8), 5.00 (ddt, $1 \mathrm{H}, J 1.6,2.0$ and 17.1, H-8), 5.80 (ddt, $1 \mathrm{H}, J 6.6,10.1$ and 17.1, H-7) and 9.77 (t, 1H, J 1.9, CHO); ${ }^{13} \mathrm{C}$ NMR $\delta 21.77$ (C-3), 28.44 (C-4), 29.55 (C-5), 33.35 (C-6), 43.68 (C-2), 114.34 (C-8), 138.53 (C-7) and 202.62 (C-1). MS (EI), $\mathrm{m} / \mathrm{z}$ (\%) $125\left(5, \mathrm{M}^{+}-\mathrm{H}\right), 97$ (12, $\left.\mathrm{M}^{+}-\mathrm{CHO}\right), 83\left(20, \mathrm{M}^{+}-\mathrm{C}_{2} \mathrm{H}_{3} \mathrm{O}\right)$, 82 (37, $\mathrm{M}^{+}-\mathrm{C}_{2} \mathrm{H}_{4} \mathrm{O}$ by McLafferty rearrangement), 73 (11), 67 (43), 60 (37), $55\left(100, \mathrm{C}_{3} \mathrm{H}_{5} \mathrm{O}^{+}\right.$, cleavage at C-3 - C-4), 54 (28) and 51 (7); these results are in good agreement with the literature data. ${ }^{7}$

\section{Acknowledgments}

The authors gratefully acknowledge CONICET, ANPCyT and Fundación Josefina Prats for financial support and A.B.J.B. is also thankful to CONICET for her fellowship. Thanks are due to Drs. V. Minkin (Rostov State University, Russia) and D. A. Bianchi (Technical University of Vienna, Austria) for helping with literature, and Drs. F. Arrighi and A. Bardón (National University of Tucumán, Argentina) are acknowledged for providing mass spectral data.

\section{References}

1. Kashiwaba, N.; Morooka, S.; Kimura, M.; Ono, M.; Toda, J.; Suzuki, H.; Sano, T.; Nat. Prod. Lett. 1997, 9, 177; da-Cunha, E. V. L.; Cornélio, M. L.; Barbosa-Filho, J. M.; Braz-Filho, R.; Gray, A. I.; J. Nat. Prod. 1998, 61, 1140.

2. Bianchi, D. A.; Bracca, A. B. J.; Schmeda Hirschmann, G.; Theoduloz, C.; Kaufman, T. S.; Bioorg. Med. Chem. Lett. 2005, 15, 2711.

3. Bianchi, D. A.; Cipulli, M.; Kaufman, T. S.; Eur. J. Org. Chem. 2003, 4701; Bracca, A. B. J.; Kaufman, T. S.; Eur. J. Org. Chem. 2007, 5284 .
4. Toth, J. E.; Hamann, P. R.; Fuchs, P. L.; J. Org. Chem. 1988, 53, 4694.

5. Takano, S.; Kawaminami, S.; Phytochemistry 1987, 26, 435.

6. Takano, S.; Kawaminami, S.; Phytochemistry 1988, 27, 1197.

7. Hirakura, K.; Morita, M.; Nakajima, K.; Ikeya, Y.; Mitsuhashi, H.; Phytochemistry 1991, 30, 3327.

8. Brotherton, R. J.; Hazlet, S. E.; J. Org. Chem. 1962, 27, 3253.

9. Bestmann, H. J.; Suss, J.; Vostrowsky, O.; Tetrahedron Lett. 1978, 3329.

10. Katopodis, A. G.; Wimalasena, K.; Lee, J.; May, S. W.; J. Am. Chem. Soc. 1984, 106, 7928.

11. Kapustina, N. I.; Popkov, A. Yu.; Gasanov, R. G.; Nikishin, G. I.; Izvest. Akad. Nauk SSSR Ser. Khim. 1988, 2327.

12. Zacharkin, L. I.; Kamernitski, D. A.; Izvest. Akad. Nauk SSSR Ser. Khim. 1981, 443.

13. Arata, K.; Nakamura, H.; Nakamura, Y.; Bull. Chem. Soc. Jpn. 1994, 67, 2351.

14. Yasuo, T.; Noriaki, Y.; JP 02-218638, assigned to Kuraray Co., Ltd; Chem. Abstr. 114:061540, 1991.

15. Tsuda, T.; Yasuo, T.; Watanabe, K.; Takashi, H.; EP 0908441; assigned to Kuraray Co., Ltd.

16. Kamitanaka, T.; Matsuda, T.; Harada, T.; Tetrahedron 2007, 63, 1429.

17. Daimon, A.; Kamitanaka, T.; Kishida, N.; Matsuda, T.; Harada, T.; J. Supercrit. Fluids 2006, 37, 215.

18. Bianchi, D. A.; Rúa, F.; Kaufman, T. S.; Tetrahedron Lett. 2004, 45, 411, and references cited therein.

19. Taber, D. F.; Deker, P. B.; Gaul, M. D.; J. Am. Chem. Soc. 1987, 109, 7488; Taber, D. F.; Green, J. H.; Geremia, J. M.; J. Org. Chem. 1997, 62, 9342.

20. Shen, X.; Wasmuth, A. S.; Zhao, J.; Zhu, C.; Nelson, S. G.; J. Am. Chem. Soc. 2006, 128, 7438.

21. Burns, D. H.; Miller, J. D.; Chan, H. K.; Delaney, M. O.; J. Am. Chem. Soc. 1997, 119, 2125, and references cited therein.

Received: December 21, 2007

Web Release Date: July 14, 2008 